Literature Review

\title{
Factors That Related To Cancer Related Fatigue
}

\section{Santoso Tri Nugroho'}

1 Pekalongan University

\section{Article Info}

\section{Article History:}

Accepted May 7th, 2019

Key words:

Fatigue; Cancer; Nursing

\section{INTRODUCTION}

Fatigue is a feeling of fatigue that includes physical, mental and emotional, described as feeling helpless or lacking in energy to do something we want or need we. ${ }^{1}$ Fatigue in cancer-related fatigue is a very common symptom and sign occurs in cancer patients and is different from fatigue experienced by healthy individuals in daily life. ${ }^{1,2}$ In normal individuals, fatigue will disappear with adequate rest and sleep, while fatigue in cancer patients is not. ${ }^{2}$

As many as $40 \%$ to $100 \%$ of cancer sufferers experience fatigue. Fatigue in

\section{Abstract}

\begin{abstract}
About $40 \%$ to $100 \%$ of cancer patients complaint of fatigue. Cancer Related Fatigue is the most disturbing symptom compared to another symptom, like nausea and vomiting. Persistent cancer-related fatigue can impact on patient quality of life because the patient becoming too tired to involve in the activity. Need study to recognize factors that related to fatigue so that as a nurse we can choose accurate nursing intervention to overcome Google search with keyword: fatigue, cancer, and nursing. Literature were in full text and published by the year 1999-2016. Literature that was in inclusion criteria than be analyzed. Result: From 6 kinds of literature that fatigue. That is characteristic (age, sex), sociodemography (economic status), stadium cancer, exercise, pain, depression, and sleep quality. But the factor that most related to cancer-related fatigue remains unclear Conclusion: Age, sex, economic status, stadium, exercise, pain, depression and sleep quality are factors that can be used as predictor fatigue.
\end{abstract}

Corresponding author:

Santoso Tri Nugroho

Santrinug01@gmail.com

South East Asia Nursing Research, Vol 1 No 1, June 2019

ISSN:2685-032X

DOI: https://doi.org/10.26714/seanr.1.1.2019.20-26

cancer patients is a symptom and a sign that is most disturbing compared to other symptoms and signs, such as pain, nausea and vomiting. ${ }^{3}$ Continuous fatigue conditions can affect quality client's life because the client becomes too tired to get involved in daily activities. ${ }^{4}$ Given these conditions, there is a need for appropriate nursing intervention to overcome fatigue in cancer clients.

Nurses as scientists, in providing nursing care must be based on an evidence base. The nursing intervention carried out must focus on the factors that are the cause of fatigue itself, so that the nursing 
interventions provided are truly effective in overcoming fatigue.

Based on this background, the authors feel the need for a study to find out the factors that are related to fatigue to determine appropriate nursing interventions to overcome fatigue in cancer clients.

The objective of this review is writing this literature study aims to identify what factors are associated with fatigue in cancer clients.

\section{METHODS}

Design of article tracking in this literature study through Google scholar and Google search, with keywords fatigue, cancer, nursing. The literature used was dated 1999-2016, full-text form and design used Observational study, prospective controlled study, 1-year longitudinal study, longitudinal study with repeated measures and systematic review. Articles that have met the criteria then analyzed narratively.

\section{RESULTS}

1. The study was conducted on 374 respondents namely gastric cancer survivor. Kuisener was in the form of a Brief Fatigue Inventory, a Beck Depression Inventory, a European Organization for Research, a QLQ-C30 Treatment of Cancer and a QLQ-STO22 gastric module that was sent by mail. It also contains questionnaires about sociodemography and characteristics of symptoms and signs. Then the data is analyzed by regression logistic model to find out the relationship between independent and dependent variables. The results showed that nearly half of gastric cancer survivors who experienced fatigue were associated with female sex, poor economic status, living in rural areas, active smokers, early-stage tumors, being depressed, and poorly performing. Depression and strong poor appearance are associated with fatigue. While the tumor stage (initial) and type of surgery contribute to worsening fatigue conditions.

2. Meta-analysis with search methods through electronic databases including PubMed, CINAHL, PsychINFO, ProQuest, and Sports Discus on journals and articles that are in accordance with the research subjects. A total of 16 results were obtained which represented 1426 respondents (exercise, 759; control, 667). Furthermore, a meta-analysis was prepared using the fixed-effects model. The results of the analysis found that aerobic exercise and musculoskeletal strength exercises were known to provide significant development to overcome fatigue in cancer patients.

3. Observational analytic research design with a cross-sectional approach. The survey was conducted, 1933 respondents filled out questionnaires sent by letter consisting of questionnaires about Brief Fatigue Inventory, Beck Depression Inventory, European Organization for Research and Treatment of Cancer QLQ-C30, and QLQ-BR23. Also includes data on sociodemography, clinics, and characteristics of symptoms. Data analysis using multivariate logistic regression. The results showed that $66.1 \%$ of mammary ca survivors had moderate to severe fatigue and $24.9 \%$ had moderate to severe depression. Both fatigue and depression are both more influenced by sociodemographic factors, comorbidity, and characteristics of symptoms and signs, than cancer and cancer treatment itself.

4. Study design Prospective controlled Cross-sectional study. The study was conducted by means of advanced cancer patients treated in 3 palliative care units included as respondents. The exclusion criteria were: Patients underwent radiotherapy or chemotherapy in the last 4 weeks, 
experienced clinical anxiety, lack of English language skills, helplessness, non-dominant hand pain, and prognosis of patients who died less than 2 weeks. The working procedure is that the researcher visits the 3 treatment units each week and approaches the identified patients can be used as research respondents. Recruitment was stopped when researchers were on vacation, or sick. Controls were subjects of the same age and sex as respondents but did not suffer from cancer, with the inclusion criteria and exclusions being the same as patients. After informed consent, patients and controls were given the same assessment, except for blood tests not performed on controls. After 2 weeks, the assessment was repeated both for the patient and the controls. The research tool consisted of Fatigue Severity Scale (FSS) to measure fatigue levels, the European Organization for Research and Treatment of Cancer Quality of Life Questionnaire (EORTC QLQ core 30) to measure quality of life, Hospital Anxiety and Depression Scale (HADS) to measure anxiety levels and depression, Three visual analog scales (VAS) to measure fatigue and weakness and ability to concentrate, The Body Mass Index (BMI) and the Mid Arm Muscle Circumference (MAMC) to measure nutritional status. Patients (not done in the control), blood cell count, routine biochemistry, and prostate cancer patients were tested for testosterone, luteinizing hormone ( $\mathrm{LH}$ ) and hormone sex binding globulin (SHBG). Spearman Rank Correlation Coefficient was used to determine the relationship of each variable. Mann-Whitney U-test was used to compare each group and Multiple regression analysis was used to identify factors that independently predicted fatigue. The results showed that fatigue was not related to age, sex, diagnosis, the metastatic process, anemia, nutritional status, muscle function, or emotional condition.
Fatigue is significantly associated with pain and dyspnea in patients and is associated with anxiety and depression in controls.

5. The study design was a 1-year longitudinal study, with the sampling technique of 107 women newly diagnosed with stage I-III mammary cesarean and scheduled to get at least 4 cycles of chemotherapy then selected according to the specified inclusion criteria. From the selection process, 68 people were included in the study. Control was women who did not have cancer included in the study as a comparison. Furthermore, each respondent (cancer sufferer) was asked to choose one of their friends to be controlled, if the respondent did not have friends, volunteers would be chosen to become control. Each friend (control) must be the same as the cancer patient in terms of age $( \pm 5$ years), ethnicity, and education. From the selection process, there were 60 people as "normal" controls. Exclusion criteria (cancer patients) are: pregnant, in a spinal cord transplant, undergoing radiotherapy, metastatic cesarean section, suffering from other diseases, anemia, and experiencing physical and psychological deterioration. While the exclusion criteria for normal controls are ever diagnosed with cancer (all types). The data collection procedure was: after respondents filled out informed consent, respondents and controls were asked to fill out questionnaires to measure the quality of sleep, fatigue, depression, and QOL. Data collection was done 3 times: before chemotherapy, at the end of 4 cycles of chemotherapy, and 1 year after chemotherapy. The time of data collection varies depending on when the patient starts chemotherapy, but always at least 3 days before chemotherapy. Descriptive analysis (mean, standard deviation, and error standard) was carried out on all 
outcomes from the 3 measurements. Ttests and Chi-square or Fisher's exact tests were used to measure differences in demographic characteristics between the two groups. Chi-square tests or Fisher's exact tests were used to examine possible differences in medical comorbidities and average dropout. The Pearson correlation is applied between variables and age and body mass index. The results showed that compared to the control group, cancer patients had longer napping times, worse sleep quality, more fatigue, more depression, more disturbed routine ratification and worse QOL (p-value <0.05). When administering 4 cycles of therapy: cancer patients showed sleep quality, fatigue, depression, and routine activity were worse than the group at the baseline level and in those without cancer (control) ( $\mathrm{p}$ values $<0.05$ ). After 1 year, fatigue, depression, and QOL in cancer patients returned to baseline levels but remained worse than the control group. While for naping time and routine activities it is no different from the control group.

6. The design of the study is longitudinal design with repeated measures, with the sampling technique of ca mammary patients visiting the medical-surgical oncology clinic selected to be used as the study sample. The inclusion criteria of this study included women diagnosed with mammary cancer (0-8 weeks), being in stage 0 -III, aged $>18$ years, able to provide informed consent, being able to fill out questionnaires every 3-6 months up to 4 years after treatment active ends, can read and write, can speak English, and has no mental disorders. From the selection process, a sample of 150 people was obtained. The research tool used is the Distress thermometer problem list, used for self-reporting about stress conditions around cancer he suffered and the psychological status of the respondent. The Brief Pain Inventory is used to measure the incidence, location, and intensity of pain. The Brief Fatigue Inventory is used to measure the level of fatigue of respondents. The Patient Health Questionnaire (PHQ9), is used to independently measure client depressive conditions. Generalized Anxiety Disorder (GAD7), is used to measure the respondents' anxiety level. Data analysis using univariate, bivariate and multivariate analysis. The results of the analysis showed that desperation, pain, and sleep disorders were significant predictors individually and collectively on fatigue $(P<0.00)$. Sleep disturbance was the most significant predictor of fatigue in the first year of patients with cesarean section. 
Table 1.

Characteristics of articles $(\mathrm{N}=6)$

\begin{tabular}{|c|c|c|c|c|}
\hline No & Title & Author (year) & Method & Results \\
\hline 1 & $\begin{array}{l}\text { Factors related to clinically } \\
\text { relevant fatigue in disease- } \\
\text { free stomach cancer } \\
\text { survivors and expectation- } \\
\text { outcome consistency. }{ }^{5}\end{array}$ & $\begin{array}{l}\text { Hwang IC et.al } \\
(2014)\end{array}$ & $\begin{array}{l}\text { Observational, } \\
\text { Cross-sectional }\end{array}$ & $\begin{array}{l}\text { Fatigue in cancer clients is related to } \\
\text { the female sex, poor economic } \\
\text { status, living in rural areas, active } \\
\text { smokers, early stages, and } \\
\text { depression, strong depression is } \\
\text { associated with fatigue, } \\
\text { compounded if the client is in the } \\
\text { early stages. }\end{array}$ \\
\hline 2 & $\begin{array}{l}\text { Exercise is an effective } \\
\text { treatment modality for } \\
\text { reducing cancer-related } \\
\text { fatigue and improving } \\
\text { physical capacity in cancer } \\
\text { patients and survivors. }{ }^{6}\end{array}$ & $\begin{array}{l}\text { Elliott M. McMillan } \\
\text { and Ian J. } \\
\text { Newhouse, (2011) }\end{array}$ & Meta-analysis. & $\begin{array}{l}\text { Exercise is related to fatigue in } \\
\text { cancer clients. Exercise (aerobic and } \\
\text { musculoskeletal strength) is } \\
\text { effective in overcoming fatigue in } \\
\text { cancer clients. }\end{array}$ \\
\hline 3 & $\begin{array}{l}\text { Fatigue and depression in } \\
\text { disease-free breast cancer } \\
\text { survivors: prevalence, } \\
\text { correlates, and association } \\
\text { with quality of life. }\end{array}$ & $\begin{array}{l}\text { Kim, S.H; Son, B.H; } \\
\text { Hwang, S.Y; Han, } \\
\text { W; Yang, J.H; Lee, } \\
\text { S; Yun, Y.H. (2008) }\end{array}$ & $\begin{array}{l}\text { The survey, } \\
\text { Cross-Sectional }\end{array}$ & $\begin{array}{l}\text { Fatigue and depression are more } \\
\text { influenced by sociodemographic } \\
\text { factors, comorbidity, and } \\
\text { characteristics of respondents. }\end{array}$ \\
\hline 4 & $\begin{array}{l}\text { Fatigue in advanced cancer: a } \\
\text { prospective controlled cross- } \\
\text { sectional study. }\end{array}$ & $\begin{array}{lr}\text { P Stone, J Hardy, K } \\
\text { Broadley, } \\
\text { Tookman, AJ } \\
\text { Kurowska and } & \text { R } \\
\text { A'Hern (1999) }\end{array}$ & $\begin{array}{l}\text { Prospective } \\
\text { controlled Cross- } \\
\text { sectional study. }\end{array}$ & $\begin{array}{l}\text { Fatigue is not related to age, sex, } \\
\text { diagnosis, the process of } \\
\text { metastasis, anemia, nutritional } \\
\text { status, muscle function, or } \\
\text { emotional condition. Fatigue is } \\
\text { significantly associated with pain } \\
\text { and dyspnea in patients and is } \\
\text { associated with anxiety and } \\
\text { depression in controls. }\end{array}$ \\
\hline 5 & $\begin{array}{l}\text { Sleep, fatigue, depression, } \\
\text { and circadian activity } \\
\text { rhythms in women with } \\
\text { breast cancer before and } \\
\text { after treatment: a 1-year } \\
\text { longitudinal study. }\end{array}$ & $\begin{array}{l}\text { Israel, S.A ; Liu L ; } \\
\text { Rissling, M ; Loki } \\
\text { Natarajan, L ; } \\
\text { Neikrug, A.B ; } \\
\text { Palmer, B.W ; Paul } \\
\text { J; Mills, P.J ; } \\
\text { Barbara A. Parker, } \\
\text { B.A ; Georgia } \\
\text { Robins Sadler, G.R } \\
\text {; and } \\
\text { Maglione, } \\
\text { (2014) }\end{array}$ & $\begin{array}{l}\text { a 1-year } \\
\text { longitudinal } \\
\text { study }\end{array}$ & $\begin{array}{l}\text { Compared to the control group, } \\
\text { cancer patients have longer } \\
\text { napping times, worse sleep quality, } \\
\text { more fatigue, more depression, } \\
\text { more disturbed routine ratification } \\
\text { and worse QOL (p values <0.05) } \\
\text { When administering } 4 \text { cycles of } \\
\text { therapy: cancer patients showed } \\
\text { sleep quality, fatigue, depression, } \\
\text { and routine activity were worse } \\
\text { than the group at the baseline level } \\
\text { and in those without cancer } \\
\text { (control) (p values <0.05) } \\
\text { After } 1 \text { year, fatigue, depression, } \\
\text { and QOL in cancer patients } \\
\text { returned to baseline levels but } \\
\text { remained worse than the control } \\
\text { group. While for naping time and } \\
\text { routine activities it is no different } \\
\text { from the control group. }\end{array}$ \\
\hline
\end{tabular}




\begin{tabular}{|c|c|c|c|c|}
\hline No & Title & Author (year) & Method & Results \\
\hline 6 & $\begin{array}{l}\text { Factors That Affect Fatigue In } \\
\text { Breast Cancer Survivors. }{ }^{10}\end{array}$ & $\begin{array}{l}\text { Ingham, Jaclyn ( } \\
\text { 2015) }\end{array}$ & $\begin{array}{lr}\text { A longitudinal } \\
\text { design } & \text { with } \\
\text { repeated } & \\
\text { measures } & \end{array}$ & $\begin{array}{l}\text { Depression, pain and sleep } \\
\text { disturbance were significant } \\
\text { predictors of individual and } \\
\text { collective fatigue }(\mathrm{P}<0.00) \text {. } \\
\text { Sleep disturbance was the most } \\
\text { significant predictor of fatigue in } \\
\text { the first year of patients with } \\
\text { cesarean section. }\end{array}$ \\
\hline
\end{tabular}

\section{DISCUSSION}

Based on the search results it was found that there were several factors that could be used as predictors of fatigue in cancer clients, namely characteristics (age, sex), sociodemography (economic status), stage of the disease, exercise, pain, depression, and sleep quality. The first study found that strong depression was associated with the onset of fatigue, and the condition was exacerbated if the client was in the early stages of cancer. The results of the first study were strengthened by fifth research which can be concluded that the more depressed the client, the more fatigued he will be. Depression is an emotional reaction in response to a sense of loss that is indicated by losing interest, difficulty concentrating and feeling hopeless to feel useless and interesting again. This condition is referred to as negative cognitive tread, this belief is seen as a basic symptom of depression, wherein it also includes somatic disorders (such as sleep disorders), motivational disorders, and affective disorders which will ultimately affect the physical condition and manifest as fatigue.

The results of the second study (systematic review) found that exercise (aerobic and muscle strengthening exercises) can reduce fatigue levels in cancer clients. This condition reinforces the notion that with increased physical activity it will provide great benefits psychologically and increase physical abilities so as to reduce the level of fatigue.
The third study was found that both fatigue and depression were both more influenced by sociodemographic factors, comorbidity, and characteristics of symptoms and signs, than cancer and cancer treatment itself. This is not in accordance with the fourth study which states that fatigue is not related to characteristics (age, sex) but is more related to pain. Pain is actually common in cancer patients, but this factor is not alone causing fatigue but is interrelated with one another. Complaints of pain that are felt continuously can cause patients to become less active, not appetite, sleep disorders, and cause patients to be depressed and depressed, all of which can cause fatigue. This can be seen in the seventh study where the results state that desperation, pain, and sleep disorders are significant predictors both alone and collectively towards fatigue.

\section{CONCLUSION}

By looking at the 6 literature we have not been able to deduce what is actually the main factor that causes fatigue in cancer clients because the results of the research are different and there are mutually reinforcing studies between one another. The main causes of fatigue in cancer clients are still unclear. However, based on these studies we know what factors might be predictors of fatigue in cancer clients, so we as nurses can focus on these factors to determine appropriate nursing interventions to overcome fatigue in cancer clients. 


\section{CONFLICTS OF INTEREST}

The author declares that none of him had any conflict of interests.

\section{REFERENCES}

1. Berger AM, Mooney $\mathrm{K}$, Alvarez-Perez A, Breitbart WS, Carpenter KM, Cella D, et al. Cancer-Related Fatigue. Off J Natl Compr Cancer Netw [Internet]. 2015 [cited 2016 Jun 20];13(8):1012. Available from: https://jnccn.org/abstract/journals/jnccn/13/ 8/article-p1012.xml

2. Howell D, Keller-Olaman S, Oliver TK, Hack TF, Broadfield L, Biggs $\mathrm{K}$, et al. A pan-Canadian practice guideline and algorithm: screening, assessment, and supportive care of adults with cancer-related fatigue. Curr Oncol [Internet]. 2013 Jun [cited 2019 Jun 20];20(3):e233-46. Available from: http://www.ncbi.nlm.nih.gov/pubmed/23737 693

3. Hinds PS, Quargnenti A, Bush AJ, Pratt C, Fairclough D, Rissmiller G, et al. An evaluation of the impact of a self-care coping intervention on psychological and clinical outcomes in adolescents with newly diagnosed cancer. Eur J Oncol Nurs [Internet]. 2000 Mar [cited 2019 Jun 20];4(1):6-17. Available from: http://www.ncbi.nlm.nih.gov/pubmed/12849 624

4. Janda M, Gerstner N, Obermair A, Fuerst A, Wachter S, Dieckmann K, et al. Quality of life changes during conformal radiation therapy for prostate carcinoma. Cancer [Internet]. 2000 Sep 15 [cited 2019 Jun 20];89(6):1322-8. Available from: http://www.ncbi.nlm.nih.gov/pubmed/11002 229

5. Hwang IC, Yun YH, Kim Y-W, Ryu KW, Kim YA, Kim S, et al. Factors related to clinically relevant fatigue in disease-free stomach cancer survivors and expectation-outcome consistency. Support Care Cancer [Internet]. 2014 Jun 9 [cited 2019 Jun 20];22(6):1453-60. Available from: http://link.springer.com/10.1007/s00520013-2110-2

6. McMillan EM, Newhouse IJ. Exercise is an effective treatment modality for reducing cancer-related fatigue and improving physical capacity in cancer patients and survivors: a meta-analysis. Appl Physiol Nutr Metab [Internet]. 2011 Dec [cited 2019 Jun 20];36(6):892-903. Available from: http://www.nrcresearchpress.com/doi/10.11 39/h11-082

7. Kim SH, Son BH, Hwang SY, Han W, Yang J-H, Lee $\mathrm{S}$, et al. Fatigue and depression in diseasefree breast cancer survivors: prevalence, correlates, and association with quality of life. J Pain Symptom Manage [Internet]. 2008 Jun [cited 2019 Jun 20];35(6):644-55. Available from:

https://linkinghub.elsevier.com/retrieve/pii/S 0885392408000614

8. Stone P, Hardy J, Broadley K, Tookman AJ, Kurowska A, A'Hern R. Fatigue in advanced cancer: a prospective controlled crosssectional study. Br J Cancer [Internet]. 1999 Mar 26 [cited 2019 Jun 20];79(9-10):1479-86. Available from: http://www.ncbi.nlm.nih.gov/pubmed/10188 894

9. Ancoli-Israel S, Liu L, Rissling M, Natarajan L, Neikrug AB, Palmer BW, et al. Sleep, fatigue, depression, and circadian activity rhythms in women with breast cancer before and after treatment: a 1-year longitudinal study. Support Care Cancer [Internet]. 2014 Sep 15 [cited 2019 Jun 20];22(9):2535-45. Available from: http://link.springer.com/10.1007/s00520014-2204-5

10. Ingham J. Factors That May Predict Fatigue in Women with Newly-Diagnosed Breast. 2015 [cited 2019 Jun 20]; Available from: https://kb.osu.edu/handle/1811/68732 